\title{
Мы готовим просвещенного потребителя
}

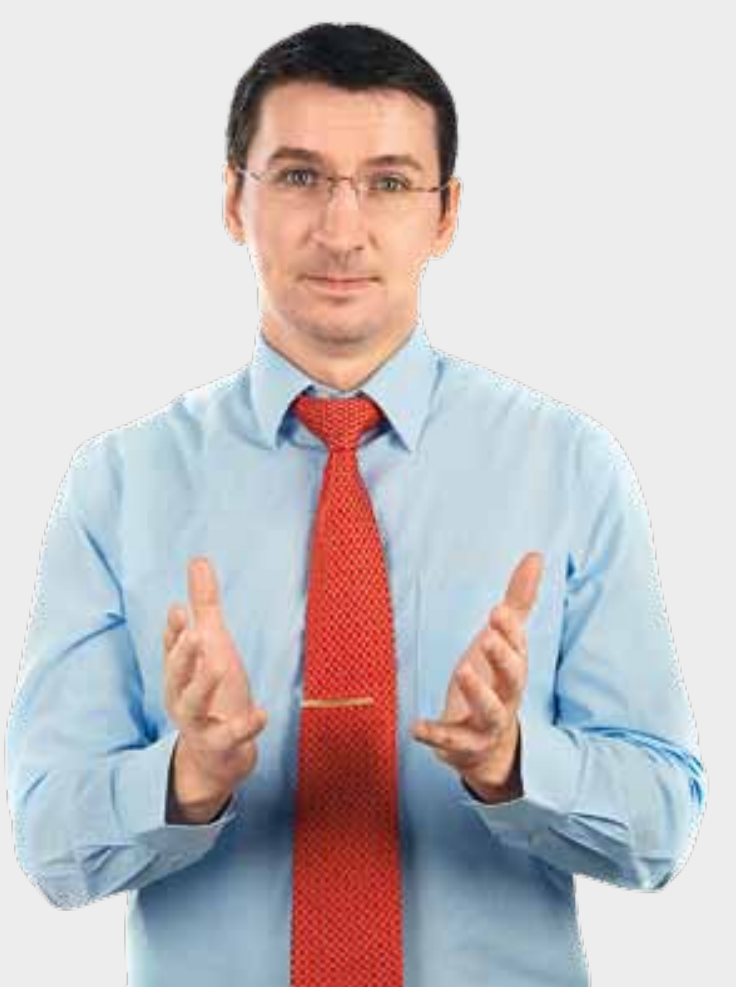

Современные высокотехнологичные производства все шире используют последние достижения сферы информационных технологий: цифровые двойники, CAD / САМ системы и новые системы учета и контроля. Без идентификации и маркировки продукции использовать такие системы в настоящем производственном процессе невозможно. При этом для массового серийного производства важно, чтобы скорость нанесения маркировки не ограничивала скорость производства изделий. Именно поэтому рынок лазерных маркировщиков быстро растет. Но также растет рынок прецизионной лазерной резки тонколистовых металлов, пластиков и других материалов. Где проходит граница, разделяющая рыночные сегменты систем лазерной гравировки и систем лазерной резки? Об этом, а также о развитии отечественного рынка лазерных станков и воспитании лазерной грамотности мы беседуем с директором по инновациям компании ООО «Лазерный Центр" Фоменко Иваном Николаевичем, кандидатом технических наук, опытным специалистом по решению нестандартных задач в сфере применения лазеров.
Иван Фоменко: Четко прослеживаемой границы между системами лазерной гравировки и системами прецизионной лазерной резки нет. В лазерных станках

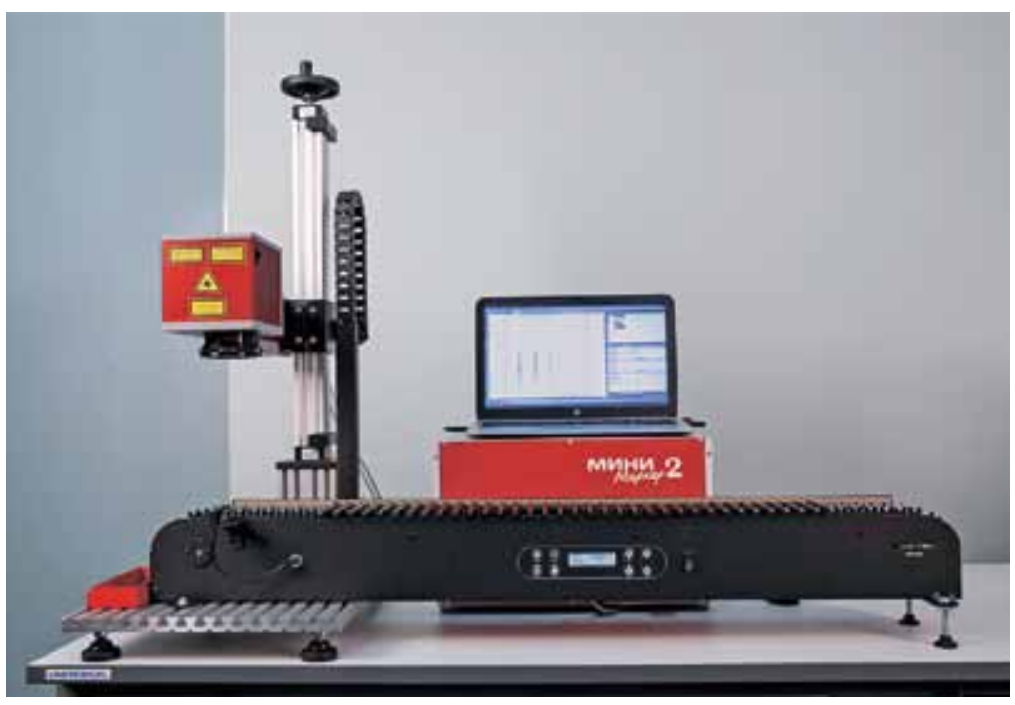

Система пазерной маркировки с конвейером для резки, гравировки и сварки используются $\mathrm{CO}_{2}$-лазеры или волоконные лазеры. Рынок промышленных систем резки и гравировки на $\mathrm{CO}_{2}$-лазерах в основном распределен между Европой и США. Многие усмехнутся, услышав это, ведь все мы видим жесткое давление Китая на Россию и на весь мир. Но сегодня рынок промышленного производства требует технологического превосходства. И в этом смысле европейские и американские станки по-прежнему занимают лидирующие позиции. Ситуации, где задачи банальны и просты и не требуют прецизионной точности и надежности, можно и нужно минимизировать цену. В этом случае китайские станки имеют существенные конкурентные преимущества. Это усиливается распространенным подходом: "заработать по-быстрому". Кому-то выгодно купить станок за 500 тысяч рублей, выполнить на нем заказ, а затем, когда станок сломается, выкинуть его и купить такой же 
новый, но дешевый под новый заказ. Это негативный факт для экономики, потому что теряется смысл "делать хорошо".

Есть и другие люди, которые выстраивают политику своего производства на несколько лет вперед. Вот для этого круга бизнесменов, работающих во всех сферах деятельности - и в промышленности, и в рекламе - и нужны станки лазерной обработки компании "Лазерный Центр". Поэтому можно говорить о цене приобретения, а можно говорить о возможностях.

Казалось бы, ну что сложного в маркировке ручек, термосов, значков. Но люди понимают, если они строят бизнес, то ситуация, когда "сегодня работает - завтра не работает", их не устраивает. Ситуация, когда "рядом 50 одинаковых бизнесменов, и я буду таким же, но 51-м", их тоже не устраивает. В бизнесе важно иметь свой стиль, выделяться, быть на голову выше других. Такие люди умеют выходить на рынок с тем, что делают быстрее других, делают качественнее, так, как никто не может. И мы даем им такую возможность с помощью нашего оборудования и технологий. В системах лазерной маркировки металла, по моим подсчетам, около трети отечественного рынка занимает продукция нашей компании, с учетом китайской экспансии.

Как сегментирован отечественный рынок промышленного лазерного оборудования?

И. Ф.: Сегодня в России есть несколько надежных компаний-производителей лазерного оборудования. Помимо продукции "Лазерного Центра" на рынке присутствуют очень хорошие производители систем лазерной сварки из Москвы. В Подмосковье делают замечательные лазерные системы для микрообработки и аддитивных технологий. В Санкт-Петербурге есть несколько российских производителей систем лазерной маркировки. По всей России есть много научных центров и частных компаний, которые занимаются решением сложных технологических задач: термоупрочнением, резкой, наплавкой, свар- кой с помощью мощных лазеров. Мы производим оборудование по схожим направлениям и часто выступаем как компании-конкуренты. Но в этом случае потребитель выигрывает, так как полу-

\section{Оборудование "Лазерного Центра" может быть инструментом, встроенным в LTCC-технологии}

чает хорошее оборудование по минимальной цене. При конкуренции с азиатскими производителями ситуация выглядит печально, так как в погоне за экономией средств потребитель забывает о целях покупки оборудования. Поэтому я лично всегда рад конкуренции с российским производителем, такой подход в целом развивает отрасль!

Кто является потребителем продукции отечественных компаний по прецизионной лазерной обработке?

И.Ф.: Если мы рассмотрим рынок промышленных лазерных систем, то он представляет собой открытую систему как для внешнего воздействия, так и для внутреннего - любой желающий может войти на рынок и свободно на

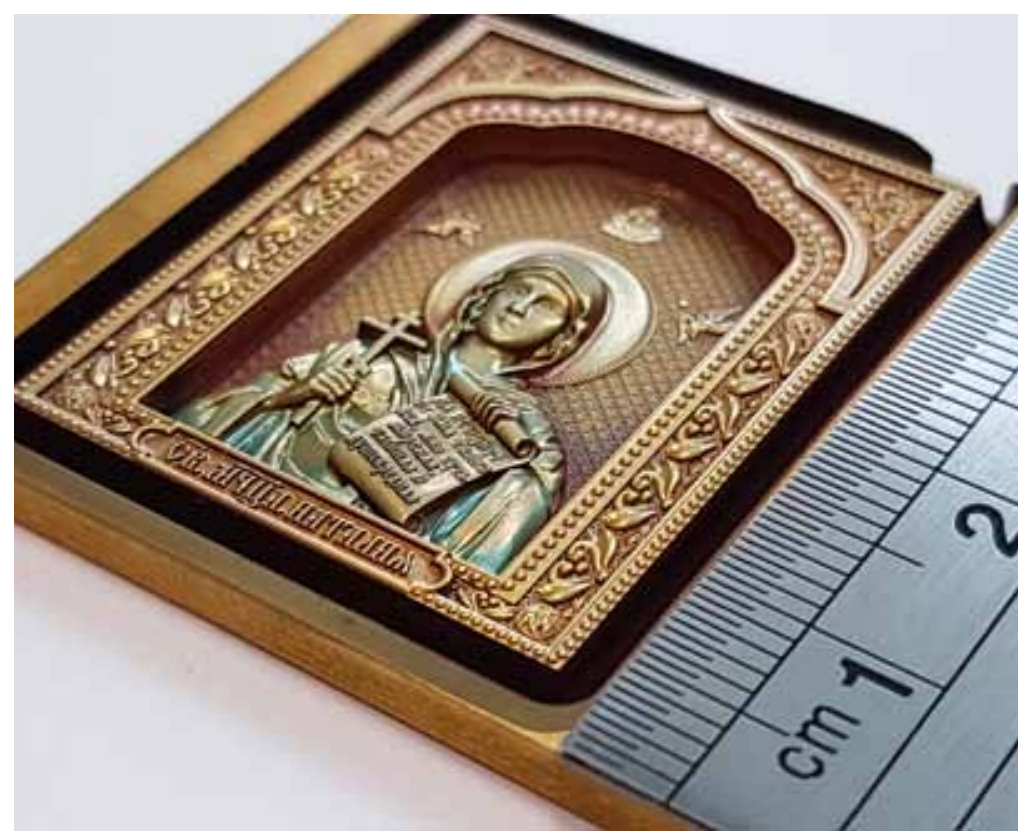

Результат LaserBarking-обработки 
нем действовать. Сейчас извне ощуща ется давление Китая. Если мы говорим о предпринимателе, который делает 5 изделий в месяц, то ему не нужны производительность и надежность. Если мы говорим о серьезной компании, которая умеет организовать свое производство и не готова вместо работы заниматься

\section{Зачем воевать с кицентами и партнерами? Надо быть мягче, добрее}

ремонтом, то дешевое оборудование, привезенное из Китая, ей не подходит. Надо сказать, что в Китае есть хорошие станки для оптоволоконной лазерной маркировки, но русские предприниматели не везут такое оборудование. Причина в том, что цена таких систем будет большой, и единственный плюс китайских дешевых систем исчезнет.

В результате возникают угрозы со стороны недобросовестных поставщиков, которые пользуются неграмотностью отечественных покупателей. В современных рыночных условиях в нашем

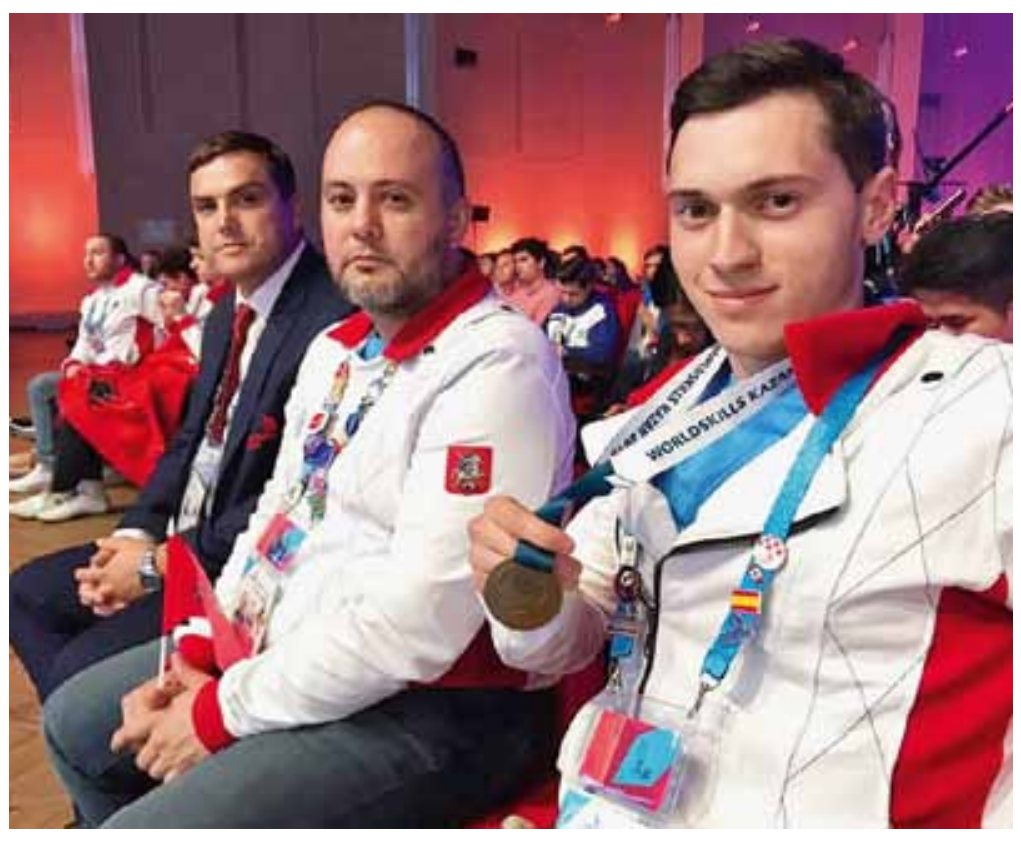

Максим Устинов - чемпион мира nо WorldSkills в компетенции "Лазерные технологии" отечестве довлеет следующая парадигма: выгодно не создавать, а выгодно убеждать и продавать. Тренинги, которых много вокруг нас, учат, как "строить" бизнес, используя современные технологии манипуляций и продаж. И заметьте, как мы все изменились как потребители: мы уже перестали доверять и верить людям. Вместо этого мы не только не ходим в магазины, мы, если находим что-то, то еще 500 обзоров про это прочитаем, чтобы получить множество подтверждений правильности своего выбора. Поэтому, чтобы продавать хорошие вещи, мне нужно потратить 90\% времени на рассказы о них и $10 \%$ - на создание. Вывод какой: инженеры в нашей стране никому не нужны, а нужны продавцы. Согласно статистическим данным 2018 года, 92\% оборудования, которое используется в нашей стране, импортное. И лишь 8\%отечественное. Но сфера промышленных лазеров - это большое исключение, доминирующую роль в этой сфере играет российский производитель, а следовательно, российский инженер, российские технологии и оборудование. И уровень нашей конкурентоспособности настолько высокий, что мы уже поставляем станки в 16 стран мира, в том числе в США, Китай, Германию, Израиль и даже на Сейшельские острова.

Каким вы видите потребителя своей продукции через пять лет?

И.Ф.: Мы вышли из Советского Союза, где каждый день борьба. На самом деле так оно и есть. Но зачем воевать с клиентами и партнерами? Надо быть мягче, добрее. Думаю, что через 5-7 лет мы будем по-другому выбирать и мыслить. Мы ждем просвещенного заказчика. Уже сегодня мы радуемся, если встречаем заказчика, который выбирает покупку между продуктами наших отечественных компаний. Мы с удовлетворением воспринимаем тот факт, что он понимает технологию. Ведь нюансов много: возникающие микротрещины, какие-то остаточные термические напряжения, изменение диэлектрических свойств при 
нагревании-охлаждении и т.д. И в дан ном случае важно понимать локальную нишу лазерных технологий в полном технологическом процессе, например в LTCC (Low Temperature Co-Fired Ceramicтехнология низкотемпературной совместно обжигаемой керамики). В таких задачах оборудование компании "Лазерный Центр" позволяет со скоростью в сотни отверстий в секунду и с точностью не хуже 5-10 мкм делать десятки тысяч таких отверстий, не повреждая основы материала. Для таких ответственных применений мы продвигаем новый интересный продукт - МикроСЕТ $(\lambda=1,05-1,07$ мкм). Это система прецизионной лазерной микрообработки материалов электронной техники. Система выполняет операции деметаллизации, формирования топологии на подложках из ситалла, нитрида алюминия и керамики, операции контурной вырезки, скрайбирования, прошивки отверстий, в том числе с управляемой конусностью, создания мезоструктур.

И действительно, внедрение лазерных систем сильно связано с образованием человека. Каждая наша продажа станка на $80 \%$ состоит из информирования о возможностях современного лазерного оборудования и современных подходах к организации процессов высокотехнологичной обработки, чему в институтах не учат. О реальных возможностях лазерного оборудования можно узнать, только придя в нашу компанию.

По каким правилам компания «Лазерный Центр" строит свою пиар-деятельность?

И.Ф.: Чтобы быть актуальными, необходимо общаться напрямую с потребителями. И даже этого зачастую бывает мало. Важно слышать потребителя и делать не то, что можешь, а то, что нужно. Соответственно PR решает две задачи: узнать, что необходимо сделать и как, а когда решение найдено, рассказать о нем.

\title{
Размер
} имеет значение

\author{
выделяйся точностью
}

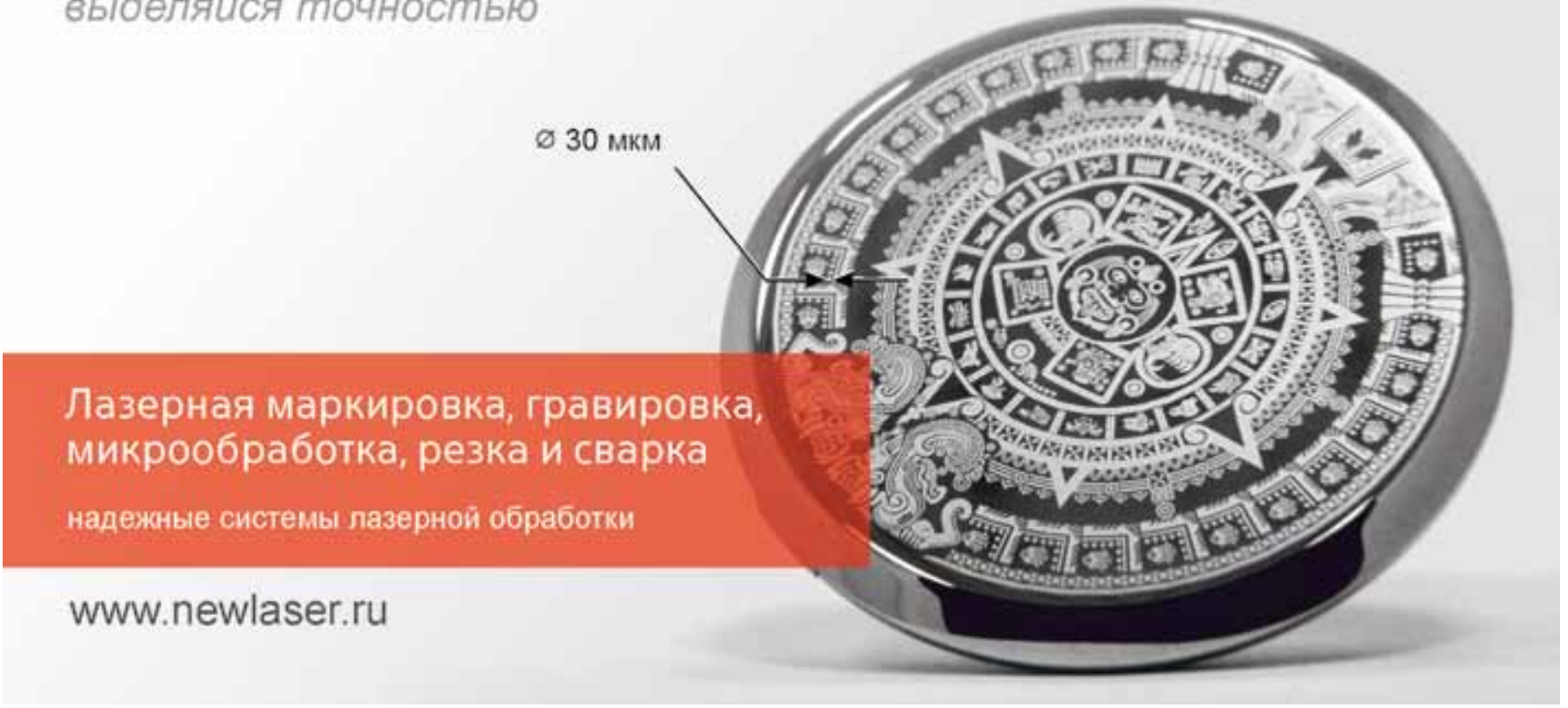

Лазерная маркировка, гравировка, микрообработка, резка и сварка надежные системы лазерной обработки
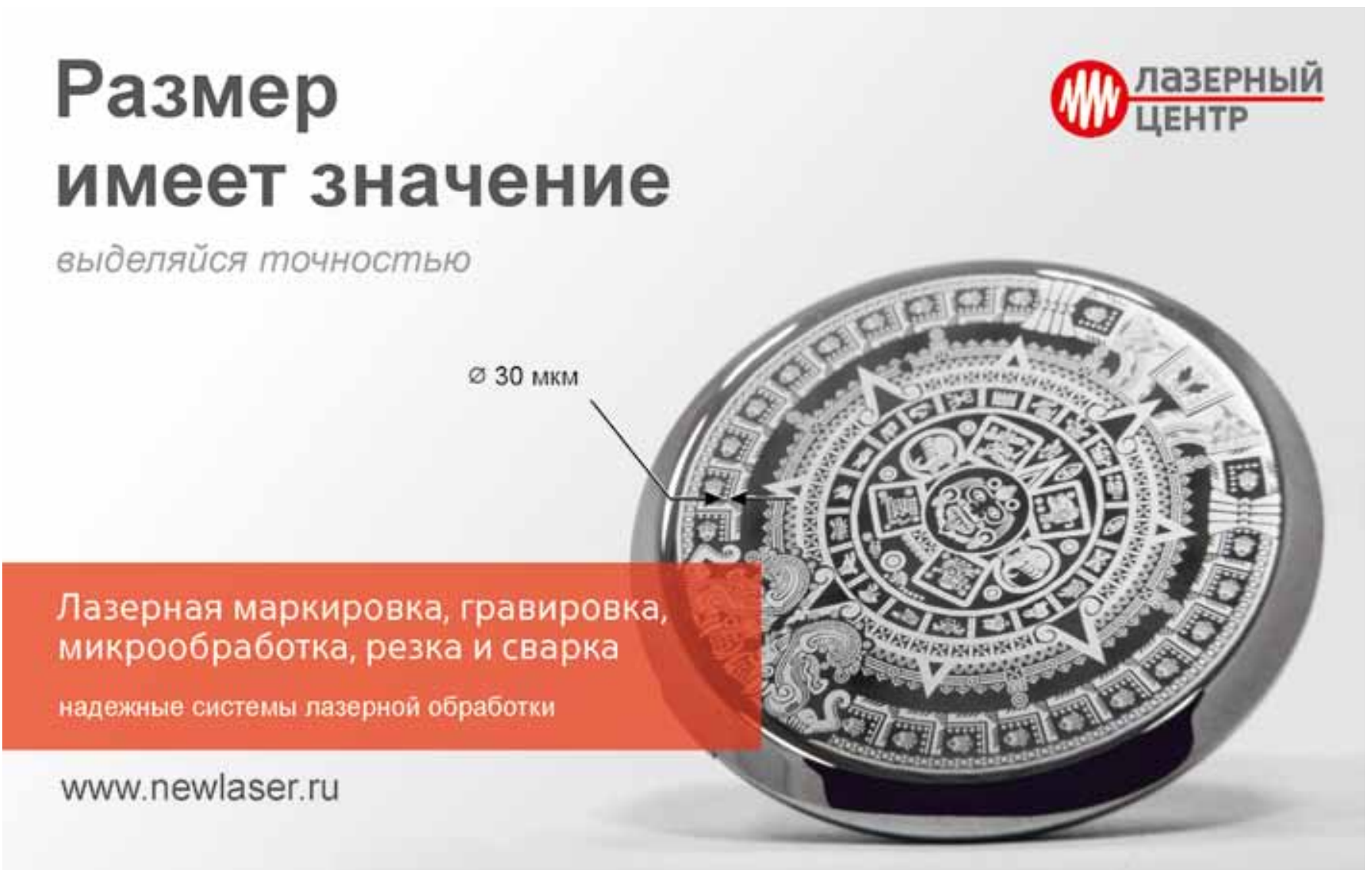
Как вы преодолеваете проблему низкой информированности общества о лазерных технологиях?

И.Ф.: Конечно, мы используем научные коммуникативные инструменты: выставки, конференции, семинары. Приглашаем на свои производственные площадки потенциальных заказчиков, проводим занятия и тренинги для клиентов. Ищем и находим все возможные пути.Есть такое движение WorldSkills, основанное в далеком 1950 году. Его цель - продвигать профессиональное, техническое обучение. Для этого по всему миру проводят WorldSkills-чемпионаты. Компания "Лазерный Центр" несколько лет инвестирует в развитие лазерной компетенции в этих чемпионатах, без всякой финансовой отдачи, для того, чтобы лазерные технологии были "по умолчанию" понятны будущим инженерам.

\section{Внедрение лазерных систем сильно связано с образованием человека}

Генеральный директор филиала компании в Казани "Лазерный Центр РТ» Николай Насонов сегодня является главным экспертом по лазерным компетенциям в этом движении. Он приложил много усилий для создания "Лазерных школ" в различных регионах нашей страны.

Маркировка имплантов
И теперь получился хороший результат, когда дети имеют доступ к самому современному лазерному промышленному оборудованию, которое безопасно и высокотехнологично. В конечном счете, это очень здорово, когда детей учат актуальным профессиям. Кроме того, занятия открывают широкие возможности для личностного проектного роста, когда дети могут спроектировать изделие и воплотить его в жизнь с помощью лазерных технологий. Создание технических конструкций или дизайнерских решений, которые можно потрогать и использовать, развивает в детях творческие способности реактивными темпами.

В 2019 году мировой чемпионат WorldSkills проходил в Казани с 22 по 27 августа. В нем приняли участие более 1300 молодых профессионалов из 63 стран и регионов. И вот вам результат - по лазерным компетенциям чемпионом мира стал студент московского колледжа связи № 54 Максим Устинов.

Компания "Лазерный Центр" активно поставляет оборудование для всех учебных заведений, которые готовят детей по компетенции "лазерные технологии". Мы стараемся идти дальше и любыми доступными способами внедрять лазеры в процесс обучения.

Рассмотрим ситуацию, когда к вам пришел просвещенный покупатель. Какая мощность у лазерных источников, которые стоят в продуктах компании "Лазерный Центр"?

И.Ф.: Прежде всего, если покупатель пришел за мощностью, то это плохо. Хорошо бы он пришел за системой для резки, маркировки или сварки. Почему плохо? Потому что мощность ни о чем не говорит. В светильнике лампочка 100 Вт, и ее свет может только освещать, а в 5 раз менее мощные лазеры (20 Вт) могут резать любые металлы. Не быстро, но могут.

Что касается лазеров, которые мы применяем в станках, то это излучатели мирового лидера из России - компании IPG-Photonics. Ее завод находится в Подмосковье, в г. Фрязино, юридическое лицо: ООО НТО «ИРЭ-Полюс". 
В системах маркировки и микрообработки мы применяем волоконные лазерные излучатели от 10 до 100 Вт. В системах лазерной сварки и резки мы применяем большое разнообразие лазеров, часть из которых является нашей разработкой, и мощность которых может достигать киловатта.

Но поясню еще раз, не надо считать, что система с лазером 100 Вт будет выполнять те же самые операции, но в пять раз быстрее, чем система с лазером в 20 Вт. Зачастую 100 Вт-система вообще не сможет решать задачи, которые решают системы мощностью 20 Вт. К примеру, технологии обработки керамики, трехмерной лазерной гравировки - лазерно-эрозионной обработки материалов LaserBarking ${ }^{\circledR}$ и другие технологии, которые мы разрабатывали более 10 лет, предъявляют большие требования и к лазерному источнику, и к системам перемещения, и к программному обеспечению.

Очень важно понимать физику формирования лазерного пучка и физику процессов, протекающих при взаимодействии лазера с материалами. Это понимание нам сегодня позволяет создавать недорогие устройства, которые решают очень непростые задачи.

И, когда мы обсуждаем параметры этих устройств, мощность лазера стоит далеко не на первом месте.

Новая технология лазерной 3D-гравировки - лазерно-эрозионная обработка материалов LaserBarking ${ }^{\circledR}$ предназначена для ювелирной промышленности?

И.Ф.: Технология LaserBarking - это один из примеров трехмерной лазерной маркировки, выполняемой специализированной системой серии ТурбоФорма. Она позволяет за несколько десятков часов изготовить пресс-форму для чеканки ювелирных изделий. На создание прессформы обычными способами на монетном дворе уходит несколько месяцев. Наша продукция пользуется спросом у многих ювелирных компаний. Для них эта технология является реальным спасением.
В ювелирной сфере у всех ювелиров есть специализация: кто-то занимается камнями, кто-то кулонами, кто-то медалями, кто-то производит высокохудожественные штампы для ювелирных заводов. Мы же предлагаем универсальные системы.

Есть очень интересная технология, когда мы просто режем из тонкого листа

\section{Технология LaserBarking - это один из примеров трехмерной пазерной маркировки}

изделие, и есть технология трехмерной лазерной маркировки. И все это функционал одного станка - ТурбоФорма. При этом нужно понимать, что ювелирному рынку не нужна просто "какая-то" обработка штампа. Нужна полированная поверхность с высокой детализацией. Многие заявляют возможность 3D-гравировки, но реальные ювелирные штампы с помощью лазера изготавливают только на нашем оборудование. И, насколько я знаю, сегодня в мире производителей оборудования для лазерной 3D-гравировки с высоким качеством поверхности и высокой детализацией насчитывается не более пяти.

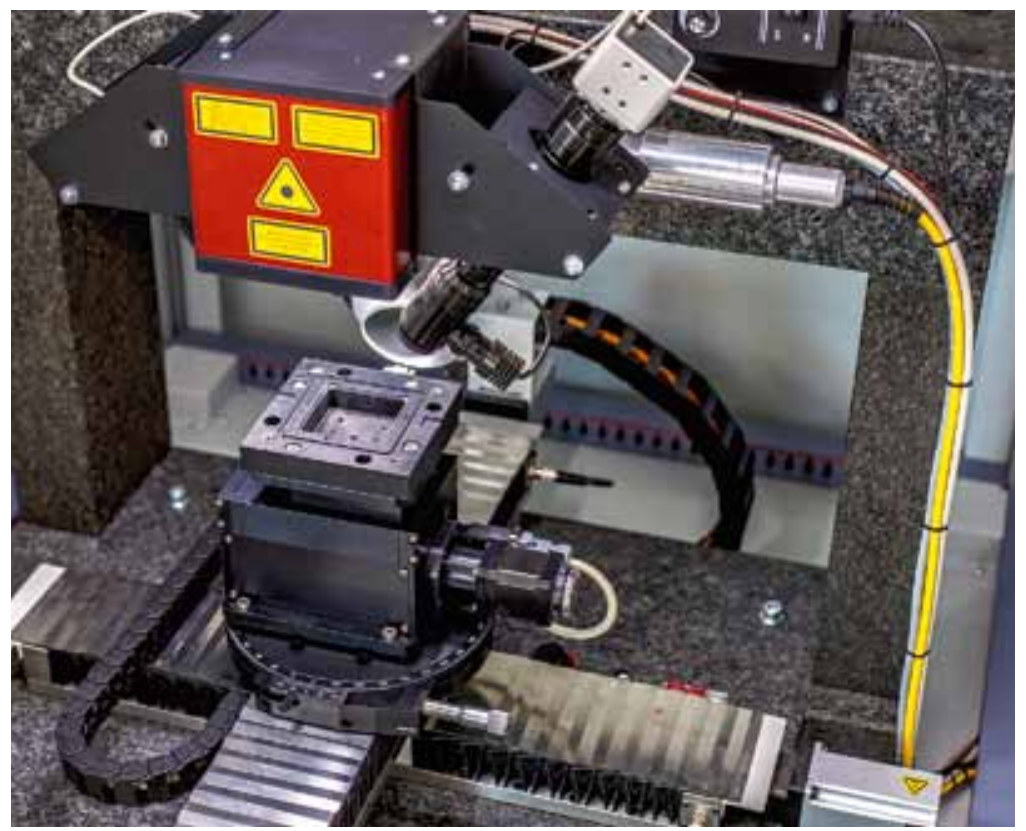

Система микрообработки МикроСЕТ 


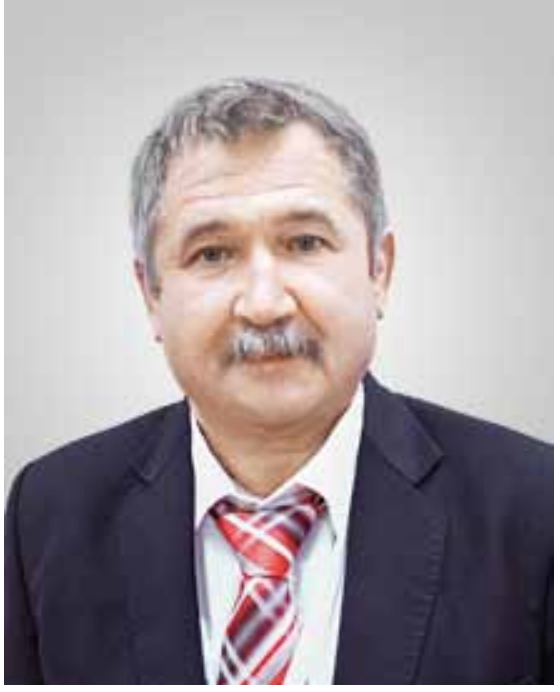

Кроме того, мар кировка, нанесенная лазером, защищает ювелирные изделия от контрафакта. Марки ровка обладает высоким разрешением и обе спечивает хранение информации об изде лии на протяжении всего его жизненного цикла. Для таких задач уже много лет с успехом используются серийные установки "Минимаркер 2".

Сергей Горный

К беседе присоединяется генеральный директор компании "Лазерный Центр" кандидат технических наук Сергей Георгиевич Горный.

Сергей Горный: Чем хорош маркировочный код? Он переводит товар в компьютерную запись. И все - дело отработано. Код маркировки несет в себе, кроме данных о продукции, необходимые параметры для управления ее движением через производственные отделы

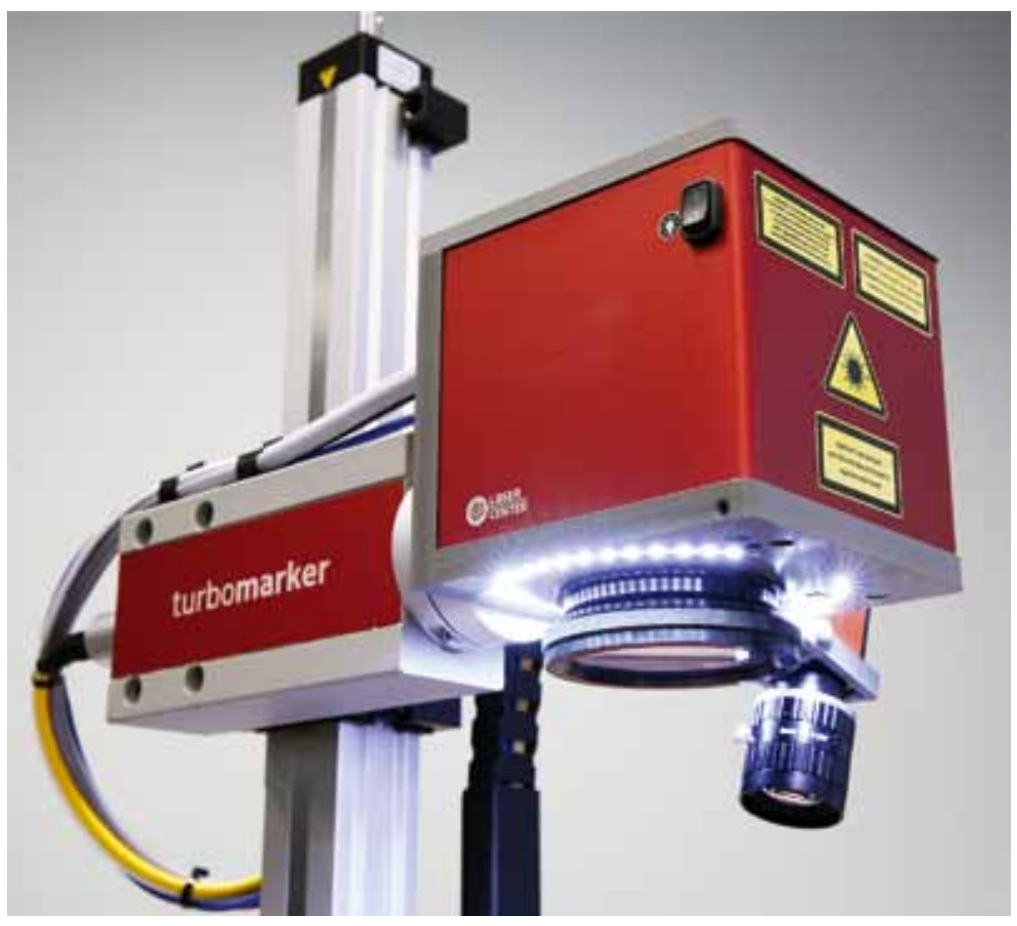

Система скоростной лазерной маркировки серии ТурбоФорма или склад, они также важны для взаимодействия с рабочими инструментами. Компания постоянно совершенствует собственное программное обеспечение. Линейка скоростных систем Турбомаркет на базе волоконного лазера предназначена для быстрой маркировки изделий из металлов, пластиков, резины. Система имеет более функциональное ПО, которое обеспечивает автоматизацию и информатизацию процессов. Так создается информационная среда для производства.

Есть ли необходимость в создании информационной среды для поиска надежных производителей лазеров?

С. Г.: Иногда покупателям кажется, что они могут создать лазерный станок самостоятельно. Мне тоже кажется, что я все могу сделать сам, когда думаю, что могу обои поклеить, сантехнику смонтировать, электрику провести дома. Это черта всех современных людей. Но, когда что-то не получается, думаю, что лучше обратиться к специалистам.

Если вы выточите линзы и соберете их вместе - эта сборка не станет объективом. Или еще одна из проблем, - а их вообще миллиард, которые могут возникнуть, - установка объектива в систему. Если возьмете объектив для волоконного лазера и просто включите его в систему, то с вероятностью 60\% у вас сгорят зеркала лазерной головки. Потому как от каждой оптической поверхности свет помимо того, что проходит вперед, еще и назад отражается. И кривизна линз часто фокусирует излучение назад - значит, сгорит покрытие зеркал. Создание общей информационной среды необходимо также для исключения ситуации попадания бизнесменов в руки мошенников, которые пишут в инструкциях перлы типа "напряжение розжига лазерной трубы" или "подача силы тока на агрегат".

Важно, чтобы каждый, кто собрался покупать лазер, знал, что лазерные системы для прецизионной обработки материалов - сложный технический объект. Лазерные системы - это путь к увеличению производительности. Прислушивайтесь к советам профессионалов! 


\section{XXVI Международный симпозиум "Оптика атмосферы и океана. Физика атмосферы"}

Институт оптики атмосферы им. В.Е.Зуева СО РАН, Институт динамики геосфер им. М.А. Садовского РАН и Институт солнечноземной физики СО РАН организуют проведение в Москве 6-10 июля 2020 года XXVI Международного симпозиума "Оптика атмосферы и океана. Физика атмосферы». Мероприятие пройдет в здании Института динамики геосфер им. академика М.А. Садовского РАН по адресу: Москва, Ленинский проспект, 38, корпус 1.

В рамках симпозиума планируется работа 5 конференций.

\section{Молекулярная спектроскопия и атмосферные радиационные процессы}

Молекулярная спектроскопия атмосферных газов. Поглощение радиации в атмосфере и океане. Радиационные процессы и проблемы климата. Модели и базы данных для задач оптики и физики атмосферы.

\section{Распространение излучения}

\section{в атмосфере и океане}

Распространение волн в случайно-неоднородных средах. Адаптивная оптика. Нелинейные эффекты при распространении волн в атмосфере и водных средах. Многократное рассеяние. Оптическая связь. Перенос и обработка изображений. Оценка достоверности метрологических измерений. Прикладные вопросы применения оптических систем и лазеров.

\section{Исследование атмосферы и океана оптическими методами}

Оптические и микрофизические свойства атмосферного аэрозоля и взвесей в водных средах. Элементный и ионный состав примесей в приземном слое атмосферы. Перенос и трансформация аэрозольных и газовых компонент в атмосфере. Лазерное и акустическое зондирование атмосферы и океана. Оптикоэлектронные комплексы для задач оптики и физики атмосферы. Мониторинг водных объектов по данным дистанционного $30 \mathrm{H}^{-}$ дирования. Диагностика растительных биосистем и биологических объектов. Активные съемочные системы для изучения атмосферы и океана.

\section{Физика тропосферы}

Структура и динамика приземной атмосферы. Динамика атмосферы и климат Азиатского региона. Результаты мониторинга тропосферы по данным обработки измерений с помощью Глобальных навигационных спутниковых систем (ГНСС). Радиофизические и оптические методы диагностики атмосферы Земли и подстилающей поверхности. Моделирование атмосферных явлений с использованием интерактивных картографических сервисов. Прогноз изменений климата.

\section{Физика средней и верхней атмосферы}

Структура и динамика средней и верхней атмосферы. Физические процессы и явления в термосфере и ионосфере Земли. Климатологические исследования верхней атмосферы. Взаимосвязь процессов в литосфере, атмосфере, ионосфере, магнитосфере и на Солнце. Развитие методов мониторинга верхней атмосферы с использованием ГНСС. Изменения глобального гравитационного поля Земли. Использование ГНСС для развития эмпирических и физических моделей.

Рабочие языки Симпозиума - русский и английский.

Сопредседатели симпозиума: академик Г.А.Жеребцов, д.ф.- м.н. Г.Г.Матвиенко, д.ф.-м.н. И.В.Пташник и д.ф.-м.н. С. Б. Турунтаев.

Вопросы можно направлять ученому секретарю Института оптики атмосферы им. В.Е.Зуева СО РАН к. Ф.-М. Н. Харченко Ольге Викторовне. Координаты: Томск, Россия, 634055, пл. Академика Зуева, 1; тел.: +7 913 874-11-00; факс: +7 3822 49-20-86; e-mail: symp2020@iao.ru.

Харченко О.В. SPHERIC and OCEAN OPTICS. ATMOSPHERIC PHYSICS

\section{ИНФРАКРАСНЫЕ ФОТОПРИЕМНИКИ $\lambda=2-8$ МКМ \\ СВЕТОДИОДЫ $\lambda=3-7$ мкм \\ ИНФРАКРАСНЫЕ ГАЗОВЫЕ СЕНСОРЫ ПИРОМЕТРИЧЕСКИЕ ДАТЧИКИ}

\section{ПРЕИМУЩЕСТВА:}

Высокая чувствительность Низкое энергопотребление Высокое быстродействие Неограниченный срок службы

\section{ПРИМЕНЕНИЯ}

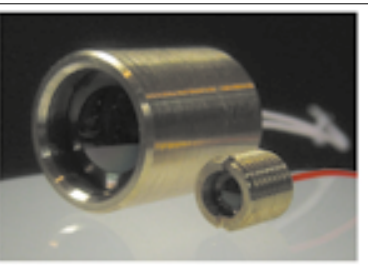

Приборы газового анализа

Низкотемпературная пирометрия

Тестирование тепловизионных систем

Тепловизоры

000 «ИоффеЛЕД»

www.ioffeled.com, Mremennyy@mallioffe.ru, +7911 2294360, Санкт-Петербург, Политехническая 26 